\title{
Nursing Students Challenges at Educational and Clinical Environment
}

\author{
Niaz Fatima M. Hussain M. Afzal M. Amir Gilani \\ Lahore School of Nursing, Name of organization, The University of Lahore Lahore, Pakistan
}

\begin{abstract}
Introduction: Nursing students are facing a series of challenges progressively in the clinical practices as well as in education system. The influence of these challenges is on their learning skills. Gape between theoretical leaning and its implementation during the course of training has impact on nursing student's empowerment. Nursing students have emphasizes on education which taught by preceptor during their training but afterword in their practice and but clinical experience has been totally difference. Nursing students conduct their clinical practice in various kinds of clinical settings. The clinical learning environment is essential for students to most likely accomplish desired learning outcomes.Methods: Descriptive cross sectional study design was used. Study conducted on nursing students and total population for this research work 160 nursing students of Allama Iqbal Medical College at Jinnah Hospital, Lahore.Results: The findings of this research indicated that from the participant's point of views were follow as, the most important challenge in the educational environment were educator follow traditional ways of teaching in their nursing care (97.1\%),no application of theoretical aspects of the nursing process in practice (69.6\%), there is a gap between practice and education system (98.1\%), the use of practice were follow as :there is a major difference what they were taught in class is similar what they practice at clinical environment $(95.8 \%)$, student not received constructive feedback from nurse educator/clinical facilitator during accompaniment (96.2\%).Conclusions: The gap between the theory and practice was an important finding. Practical-orientation and traditional view of educators, students and nurses about clinical competency based on practical skills that reduced the need of practice based on knowledge and research. Efforts to reduce the problems between the theory and practice in academic and clinical environment are needed to improve training of student nurses. Also education of professionalism and action based on work environment may be useful.
\end{abstract}

Keywords- Challenges, Nursing students, Educational environment, Clinical environment

DOI: $10.7176 / \mathrm{JHMN} / 62-06$

Publication date:May $31^{\text {st }} 2019$

\section{Introduction}

Nursing students are facing a series of challenges progressively in the clinical practices as well as in education system. The influence of these challenges is on their learning skills. Therefore, Lack of implementation nursing process in training period is one of the major problems in clinical area. Implementation of the nursing process in practical nursing are not achieving due to poor practices. Students have no knowledge about the principles of action in nursing process. Almost $90 \%$ staff nurses have poor knowledge about implementation of nursing process in practice. Due to lack of this knowledge they are unable to provide proper care in clinical placement (Hagos, Alemseged, Balcha, Berhe, \& Aregay, 2014).

During the training of nursing profession students nurses have faces many hurdles, which ultimately put a negative perception on the personality of nursing students and professional growth. A clinical placement is an authorized section of place in which students attend structured clinical experience as a part of specific unit. Many students report that clinical placement is most challenging part of learning. However, student nurses follow a number of policies and requirements in clinical setting (Fairbrother, Nicole, Blackford, Nagarajan, \& McAllister, 2016).

The problems which influence the learning in clinical and academic placement are inappropriate clinical practices and unsuitable programming of clinical education. Nursing education encompasses on academic education and clinical practice. Gap between learning and practice is serious issue in nursing education (Rafiee, Moattari, Nikbakht, Kojuri, \& Mousavinasab, 2014).

Gape between theoretical leaning and its implementation during the course of training has impact on nursing student's empowerment. In clinical setting the factor which students are facing such as not use of evidence base practice, not implementation of nursing process in practice, shortage of time for implementation, lack of facilities in clinical site, lack of knowledge about advantages and disadvantages of scientific function in clinical placement etc. There are different problems which students are facing during their academic training. The major problems are such as course content is not relevant to clinical need; educators follow traditional ways of teaching and theoretical content based on specific knowledge (SHARGHI, ALAMI, KHOSRAVAN, MANSOORIAN, \& EKRAMI, 2015).

Nursing students have emphasizes on education which taught by preceptor during their training but afterword in their practice and but clinical experience has been totally difference. Nursing students conduct their clinical 
practice in various kinds of clinical settings. The clinical learning environment is essential for students to most likely accomplish desired learning outcomes (Bisholt, Ohlsson, Engström, Johansson, \& Gustafsson, 2014).

Nursing education has lot of clinical experience in various aspects; it is effective on the nursing profession development. Therefore, it is widely used in teaching and learning of undergraduate nursing students. Clinical learning environment objective has to empower nursing students to develop clinical competences and socialization in nursing profession. These events occur in complex and dynamic learning environment that called clinical learning environment (Baraz, Memarian, \& Vanaki, 2015).

Clinical learning environment can be described as a network of forces experience by nursing students during their training period. Clinical learning atmosphere is considered a primary area of professional practice of nursing students (Papathanasiou, Tsaras, \& Sarafis, 2014).

To improve the quality of nursing student's education and learning it is necessary to evaluate the obstacles which influence on the nursing students learning and on their professional growth. Clinical learning environment not only influences the educational goals, but also effect career choices of nursing students. Learning atmosphere reflects the accessibility to the unit staff interest in intern nurses' supervision and presence of meaningful and multidimensional learning situation (Hussein, Everett, Ramjan, Hu, \& Salamonson, 2017).

Nursing educators are responsible for learning of students in academic setting as well in the clinical practice. The development of competent practice is a primary goal of nursing education. But unfortunately high qualified persons are not available in the clinical site. Thus, in the clinical area students are not able to relate theory to practice (Rafiee et al., 2014).

Clinical learning is basic factor of nursing education. Nursing students, exposure to clinical environment the most important element affects teaching process in clinical settings. Reorganization difficulties of nursing students in the clinical learning environment could improve quality of skills and performance of nursing students (Jamshidi, Molazem, Sharif, Torabizadeh, \& Najafi Kalyani, 2016).

Nursing students conduct their clinical practice in various kinds of clinical settings. The clinical learning environment is essential for students to most likely accomplish desired learning outcomes (Bisholt et al., 2014).

Clinical instructor influence the student's learning greatly who eventually graduate and shape nursing practice. The behavior of clinical instructors plays a significant role in the development of professional nursing skills. Teacher enhance the characteristics of students such as professional knowledge, role modeling and clinical competence (Ismail, Aboushady, \& Eswi, 2015)

Shortage of time and burden of work is one of the problems which students face during clinical practices. Shortage of timing and burden of work is the basic reason of gap between learning and practices for students in clinical site (Jackson, 2015).

Traditional oriented ways of teaching create poor clinical practices for nursing students. Traditional ways of teaching not play a vital role in the learning process. It effects the utilization of clinical practices. There is no close collaboration between clinical practices and nursing schools. Traditional practices not promote positive attitude for the improvement of clinical training (Zhou et al., 2015).

The nursing education system does not offer theoretical content related to clinical requirement. Therefore, student faces the problems during acquiring knowledge. Education system not enhances the knowledge according to clinical need (Shahzadi et al., 2017).

Education system not introduces the students to the clinical environment. Clinical environment includes outpatient, in-patient wards and social environment. When students are in class room they are unaware of clinical environment. After interaction with clinical placement they feel ambiguous and strange while performing their skills. Clinical setting is the situation which increases the knowledge and makes the understanding of the real picture of practical environment. In addition, learning and practice remains always different (Arabshahi, Haghani, Bigdeli, Omid, \& Adibi, 2015).

The Incompetent nurses in clinical atmosphere would be the risk to public's health. Furthermore, this is the indications of client's dissatisfaction. Lack of authentic applications in the practical creates incompetency (Cheraghi, Salsali, \& Safari, 2010).

Knowledge of learning theories, have a key value in education psychology, and very important in education. During last century, improvement and testing of the learning theories have helped to nurses especially to see how to identify people way of thinking, and changes in the techniques for considering, emotions, and behavior. It is very important to learning and implementation of learning theories who dealing with teaching and training subject. Theories of learning are the system of the structure and rules that focus on the representation and clarification of the people's learning (Aliakbari, Parvin, Heidari, \& Haghani, 2015).

Effective clinical teaching knowledge and behavior of clinical teacher are both fundamental to the clinical preparing and entry level position understanding of students. The learning of the students in a clinical setting is very affected by qualities of clinical educator. In this way it is essential that clinical instructor must to know her part and obligations and effective clinical teaching skills to manage their students in clinical site (Bawadi, Norrie, \& Debbie). 
Nursing students gain knowledge from the clinical instructor attitude, content information, clinical skills and their teaching method (Koy, 2015) Student encouraged for learning by different following teacher qualities like giving feedback (constructive) to the students on time, encourage for skill practices by assign work, set the learning objective and provide different teaching skills for effective clinical teaching (Papathanasiou et al., 2014).

\section{OBJECTIVE OF THE STUDY}

To evaluate nursing student challenges at educational and clinical environment.

\section{SIGNIFICANCE OF THE STUDY}

This study will give sufficient information regarding multiple factor which influence on nursing students professional growth. On the behalf of this study policy maker will minimize the problems which influence the academic learning and clinical practices among nursing students through conducting seminar and workshops, which enhance the academic learning and clinical performance of students. Furthermore, quality of learning will be improved in the organization which will enhance organizational prestige. The findings of this study will help to establish basis for under graduation students. The results will help the students as well as instructors to minimize their problem during learning and practice. It will also helpful in the improvement of clinical skills, competences and academic performances of the students. The findings of this research will enhance participant's knowledge regarding problems in learning and practice. They would be overcome these problems by research results. It will be helpful for me to enhancing my knowledge regarding learning and practice gap of nursing students. It is helping for me in conducting research. The results and recommendation of the studies will be helpful for other researchers to conduct more researches.

\section{LITERATURE REVIEW}

The close relationship between clinical and the educational training has a unique place in nursing profession. Study in Iran that clinical skill of the nurses, and specialty, the newly graduated nurses is not perfect in the ideal clinical practice. results revealed from the students of Iranian Medical University that imperative theoretical and clinical issues $(88.9 \%)$ related to academic are not practiced in clinical areas, $(85.6 \%)$ theoretical aspects of the nursing procedure are not being applied in practice $(81.1 \%)$ teachers are not knowledgeable and professional educators. (75.6\%) are not follow traditional routine-oriented ways in their nursing care (SHARGHI et al., 2015).

Furthermore a study revealed that there are many problems in using of evidence-based method, appropriate procedure performance in the students of Tehran. Results show that $56 \%$ has low experimental capability involved in nurse training. $63 \%$ students not prepared the checklist before going to clinical area and not inform the instructor that the main objectives are achieved during the care sector. This problem is very common in today nursing student's clinical instructor not try to minimize these gaps of clinical practices (Kenari, 2014).

In additionally the results of a study revealed that $86.5 \%$ insufficient time for performance based on knowledge connection to the nurses workload, $85.2 \%$ weakness of function encouragement systems in clinical and $75.6 \%$ are not learnt about theoretical subjects and not come into training in clinical fields after graduation. clinical instructors not do much efforts to reduce the gap between the theoretical and practical (clinical function) they are not try to improve knowledge in educational and work environment for the betterment of qualified nurses (Liu \& Aungsuroch, 2018).

Another study found in Technical Nursing Institute Cairo University Egypt that $70.8 \%$ of students' are not fulfillment by their clinical placement. $74.8 \%$ students are not prepared well for the required competencies in clinical placement. $67.4 \%$ student less satisfied due to no professional support during clinical placement. Most of the students received learning support from the clinical supervisors but not receive much attention from their clinical instructors. In spite some staff nurses are interested to help new graduate students in clinical placement; they are not much aware of the skills and strategies in clinical training and not act as a clinical instructor. Therefore, deficiency lack of well experienced staff impact on students' fulfillment with clinical placement which weaken the clinical skills of students(Grimm, 2017).

The findings obtained from the study that $50 \%$ students are inadequate communication, insufficient preparation, and enthusiastic responses in the clinical training. Moreover, $45.5 \%$ student's lack of ability in confronts the clinical environment. Student's lacks of information, insufficient preparation for entering the clinical environment destroy their learning processes and make them anxious. It's a teachers' responsibilities to treat nursing students properly in the clinical training, as well as increasing their confidence and reduce their fears because nursing teachers to be a role model for students (Jamshidi et al., 2016).

According to a research that the Greeks nursing learners have encouraging perception of clinical education environment in pediatric hospitals while there is still room for enhancement. The current scale is appropriate instrument for calculation of clinical training by learners. The questionnaire was formed by researchers and contained of thirty four questions. Questionnaire comprised questions about demographic characteristics and four parts of clinical training. They determine that nursing learners in their learning were mollified with clinical educational environment (Dafogianni, Alikari, Galanis, Gerali, \& Margari, 2015).

Mohamed reported that nursing learners underlined negative regions that could be occupied into attention by 
the faculty followers, clinical teachers, and clinical staff to improve education in clinical situation. Approval with clinical assignment and learning self-efficacy was openly proportionate to learners' accomplishment (Al Sebaee, Aziz, \& Mohamed, 2017).

\subsection{METHODS}

Research Design:

Descriptive cross sectional study design was used in this study.

Research Setting:

The setting for this study was Allama Iqbal Medical College at Jinnah Hospital, Lahore.

Study population:

Study population for this research work was the general nursing students of Allama Iqbal Medical College at Jinnah Hospital, Lahore. Total populations of nursing students were 160 .

\section{Sample Size:}

Sample size was determined by using the formula. This formula is given as follows.

$\mathrm{n}=\mathrm{N} / 1+\mathrm{N}(\mathrm{e})^{2}$

(n)=sample size, $\mathrm{N}=$ Total population, $(\mathrm{e})=$ margin of error

$\mathrm{n}=\mathrm{N} / 1+(0.05)^{2}$

$\mathrm{n}=\mathrm{N} / 1+\mathrm{N}(0.05)^{2}$

$\mathrm{n}=160 / 1+160(0.0025)$

$\mathrm{n}=160 / 1+0.5$

$\mathrm{n}=160 / 1.5$

$\mathrm{n}=106$

Sampling technique:

(Khalil, Majeed, Bio, \& Gilani, 2017)

Convenient sampling was used for the data collection.

\section{ANALYZE DATA}

The data were entered in Microsoft Excel and were computed by SPSS version 25. Descriptive statistics used include; percentage and frequency was utilized for selected demographic profile and challenges at educational and clinical environment.

\section{RESULTS}

In this chapter data analysis and data interpretation was discussed by table and graphs. Tables are shows that the demographics, challenges related to educational and clinical environment in the form of frequency and percentage along with normality test.

Section 1:

This section represents the distribution of the participant by demographic characteristics. The data is summarized in terms of frequency and percentage.

Table 1:

Description of Demographic Characteristics of participants

\begin{tabular}{|c|l|c|c|}
\hline \multirow{2}{*}{ Characteristics } & \multirow{2}{*}{ Category } & \multicolumn{2}{|c|}{ Respondents } \\
\cline { 2 - 4 } & & Number & Percent \\
\hline \multirow{2}{*}{ Gender } & Female & 106 & $100 \%$ \\
\hline \multirow{2}{*}{ Academic Year } & $21-25$ years & 71 & $67 \%$ \\
\cline { 2 - 4 } & $26-30$ years & 35 & $33 \%$ \\
\hline \multirow{3}{*}{ Last Year GPA } & $2^{\text {nd }}$ Year & 9 & $8.5 \%$ \\
\cline { 2 - 4 } & $3^{\text {rd }}$ Year & 55 & $51.9 \%$ \\
\cline { 2 - 4 } & $4^{\text {th }}$ Year & 9 & $39.6 \%$ \\
\hline \multirow{3}{*}{ Started } & $2.5-3.0$ & 55 & $8.5 \%$ \\
\cline { 2 - 4 } & $3.1-3.5$ & 42 & $51.9 \%$ \\
\cline { 2 - 4 } & $3.6-4.0$ & 46 & $39.6 \%$ \\
\hline \multirow{2}{*}{ Year in which Training } & 2015 & 51 & $43.4 \%$ \\
\cline { 2 - 4 } & 2016 & 9 & $48.1 \%$ \\
\cline { 2 - 4 } & 2017 & $8.5 \%$ \\
\hline
\end{tabular}

Table 1 shows that data was collected 106 respondents. Most of the participants $n=71,(67 \%)$ were $21-25$ years old. All participants $n=106,(100 \%)$ were females. The majority of participants $n=55,(51.9 \%)$ were $3^{\text {rd }}$ year students. Among all most of students $n=55,(51.9 \%)$ was got last year GPA between 3.1-3.5. Most of participant $\mathrm{n}=51,(48.1 \%)$ were started their training in 2017 . 
Table: 2

Table 2 represents the challenges at educational and clinical learning environment in the form of percentage on five point Likert scale.

Challenges perceived by student nurses at educational and clinical learning environment

$1=$ strongly agree $2=$ Agree $3=$ Neutral $4=$ strongly disagree $5=$ Disagree

\begin{tabular}{|c|c|c|c|c|c|}
\hline Statement & SA & $\mathbf{A}$ & $\mathbf{N}$ & SD & DA \\
\hline \multicolumn{6}{|l|}{ Challenges of clinical environment } \\
\hline $\begin{array}{l}\text { When allocated in the clinical learning environment, I was } \\
\text { supported by preceptor and clinical facilitator }\end{array}$ & $\mathbf{0 \%}$ & $2.8 \%$ & $19.8 \%$ & $32.1 \%$ & $45.3 \%$ \\
\hline $\begin{array}{l}\text { The period I was allocated in different wards was enough to } \\
\text { promote learning in relation to my level of training }\end{array}$ & $\mathbf{0 \%}$ & $11.3 \%$ & $3.8 \%$ & $26.4 \%$ & $58.5 \%$ \\
\hline $\begin{array}{l}\text { When allocated to clinical learning environment, I received } \\
\text { support visits from nurse educator/clinical facilitator }\end{array}$ & $\mathbf{0 \%}$ & $4.7 \%$ & $10.4 \%$ & $24.5 \%$ & $60.4 \%$ \\
\hline $\begin{array}{l}\text { I received constructive feedback from the nurse } \\
\text { educator/clinical facilitator during accompaniment }\end{array}$ & $\mathbf{0 \%}$ & $.9 \%$ & $2.8 \%$ & $41.5 \%$ & $54.7 \%$ \\
\hline $\begin{array}{l}\text { What I was taught in class is similar to what I practiced at } \\
\text { clinical environment }\end{array}$ & $\mathbf{0 \%}$ & $0 \%$ & $3.8 \%$ & $36.4 \%$ & $59.4 \%$ \\
\hline $\begin{array}{l}\text { There is a relationship between services rendered and teaching } \\
\text { and learning of students }\end{array}$ & $\mathbf{0 \%}$ & $40.6 \%$ & $12.3 \%$ & $7.5 \%$ & $39.6 \%$ \\
\hline $\begin{array}{l}\text { Clinical skills in relation to my level of training were available } \\
\text { at the clinical facility }\end{array}$ & $\mathbf{0 \%}$ & $5.7 \%$ & $14.2 \%$ & $24.5 \%$ & $55.7 \%$ \\
\hline $\begin{array}{l}\text { Clinical learning objectives were available at clinical } \\
\text { environment }\end{array}$ & $21.7 \%$ & $41.5 \%$ & $2.8 \%$ & $8.5 \%$ & $25.5 \%$ \\
\hline $\begin{array}{l}\text { I was delegated clinical duties in relation to my clinical } \\
\text { learning objectives }\end{array}$ & $\mathbf{0 \%}$ & $30.2 \%$ & $13.2 \%$ & $17.0 \%$ & $39.6 \%$ \\
\hline $\begin{array}{l}\text { I was allocated to work night duty where learning } \\
\text { opportunities were limited }\end{array}$ & $33.0 \%$ & $62.3 \%$ & $4.7 \%$ & $\mathbf{0 \%}$ & $\mathbf{0 \%}$ \\
\hline $\begin{array}{l}\text { Clinical staff were happy about my presence in the clinical } \\
\text { environment }\end{array}$ & $21.7 \%$ & $50.0 \%$ & $6.6 \%$ & $6.6 \%$ & $15.1 \%$ \\
\hline I had a good relationship with the clinical staff & $29.2 \%$ & $37.7 \%$ & $16.0 \%$ & $5.7 \%$ & $12 \%$ \\
\hline I was respected as a student nurse by clinical staff & $\mathbf{0 \%}$ & $5.7 \%$ & $\mathbf{1 7 . 0 \%}$ & $23.6 \%$ & $\mathbf{5 3 . 8 \%}$ \\
\hline $\begin{array}{l}\text { Clinical staff knew my level of training and learning } \\
\text { objective }\end{array}$ & $\mathbf{0 \%}$ & $7.5 \%$ & $23.6 \%$ & $21.7 \%$ & $47.2 \%$ \\
\hline $\begin{array}{l}\text { Clinical staff used procedure manual to guide me as student } \\
\text { nurse }\end{array}$ & $\mathbf{0 \%}$ & $3.8 \%$ & $22.6 \%$ & $22.6 \%$ & $50.9 \%$ \\
\hline I had confidence when practicing in the clinical environment & $\mathbf{0 \%}$ & $5.7 \%$ & $46.2 \%$ & $6.6 \%$ & $41.5 \%$ \\
\hline I was treated as part of health team by clinical staff & $5.7 \%$ & $28.3 \%$ & $38.7 \%$ & $7.5 \%$ & $\mathbf{1 9 . 8 \%}$ \\
\hline I was allowed to go for clinical assessment by ward staff & $.9 \%$ & $5.7 \%$ & $23.6 \%$ & $14.2 \%$ & $55.7 \%$ \\
\hline $\begin{array}{l}\text { The operational manager ensured that I was taught during } \\
\text { allocation }\end{array}$ & $\mathbf{0 \%}$ & $\mathbf{0 \%}$ & $4.7 \%$ & $34.9 \%$ & $60.0 \%$ \\
\hline The operational manager knew my learning objectives & $\mathbf{0 \%}$ & $.9 \%$ & $3.8 \%$ & $25.5 \%$ & $69.8 \%$ \\
\hline \multicolumn{6}{|l|}{ Challenges of educational Environment } \\
\hline Non-use of research results in clinical wards & $30.2 \%$ & $31.1 \%$ & $\mathbf{0 \%}$ & $14.2 \%$ & $24.5 \%$ \\
\hline Failure to implement of the nursing process in practice & $9.4 \%$ & $60.4 \%$ & $24.5 \%$ & $1.9 \%$ & $3.8 \%$ \\
\hline $\begin{array}{l}\text { Nurses with MSc degree teaches in the Nursing faculties not } \\
\text { in clinical ward. }\end{array}$ & $38.7 \%$ & $57.5 \%$ & $3.8 \%$ & $\mathbf{0 \%}$ & $\mathbf{0 \%}$ \\
\hline $\begin{array}{l}\text { Educators following traditional ways of teaching in their } \\
\text { nursing care on the wards. }\end{array}$ & $37.7 \%$ & $59.4 \%$ & $2.8 \%$ & $\mathbf{0 \%}$ & $\mathbf{0 \%}$ \\
\hline There is a gap between treatment and education system. & $34.9 \%$ & $63.2 \%$ & $1.9 \%$ & $\mathbf{0 \%}$ & $\mathbf{0 \%}$ \\
\hline $\begin{array}{l}\text { Educators use problem solving method in order to track } \\
\text { students' learning. }\end{array}$ & $0 \%$ & $65.1 \%$ & $12.3 \%$ & $6.6 \%$ & $16.0 \%$ \\
\hline $\begin{array}{l}\text { Educators' weaknesses in scientific procedures based on } \\
\text { theoretical courses in the internship environment }\end{array}$ & $.9 \%$ & $65.1 \%$ & $31.1 \%$ & $1.9 \%$ & $.9 \%$ \\
\hline $\begin{array}{l}\text { Teaching the theoretical subjects based on specific knowledge } \\
\text { of nursing. }\end{array}$ & $36.8 \%$ & $63.2 \%$ & $\mathbf{0 \%}$ & $\mathbf{0 \%}$ & $\mathbf{0 \%}$ \\
\hline $\begin{array}{l}\text { The amount of time is enough to devote teaching special } \\
\text { nursing knowledge }\end{array}$ & $\mathbf{0 \%}$ & $73.6 \%$ & $7.5 \%$ & $5.7 \%$ & $13.2 \%$ \\
\hline Relevance of theoretical course's content and clinical needs. & $29.2 \%$ & $63.2 \%$ & $5.7 \%$ & $.9 \%$ & $.9 \%$ \\
\hline
\end{tabular}

Views of the participant has been merged into two categories strongly disagree + disagree are to be consider as disagree and agree + strongly agree are to be consider as agree. $61.3 \%$ participant was agreeing that Non-use of 
research results in clinical wards but $39.7 \%$ were disagreeing. $69.4 \%$ were agreeing that Failure to implement of the nursing process in practice but 5.7\% were disagree. $96.2 \%$ were agreeing that Nurses with MSc degree teaches in the Nursing faculties not in clinical ward but 3.8\% participant were disagreeing. 97.1\% were agreeing that Educators following traditional ways of teaching in their nursing care on the wards but $2.9 \%$ were disagree. $98.1 \%$ were agree that there is a gap between treatment and education system but only $1.9 \%$ give neutral comment. $65.1 \%$ participants were agreeing that Educators use problem solving method in order to track students' but $29.1 \%$ were disagree learning. 66\% were agreeing that Educators' weaknesses in scientific procedures based on theoretical courses in the internship environment but $2.8 \%$ were disagreeing. $100 \%$ were agreeing that teaching the theoretical subjects based on specific knowledge of nursing. $73.6 \%$ were agreeing that the amount of time is enough to devote teaching special nursing knowledge but 18.9\% were disagreeing. 92.6\% were agreeing that Relevance of theoretical course's content and clinical needs but $1.8 \%$ were disagreeing.

\section{Figure: 1}

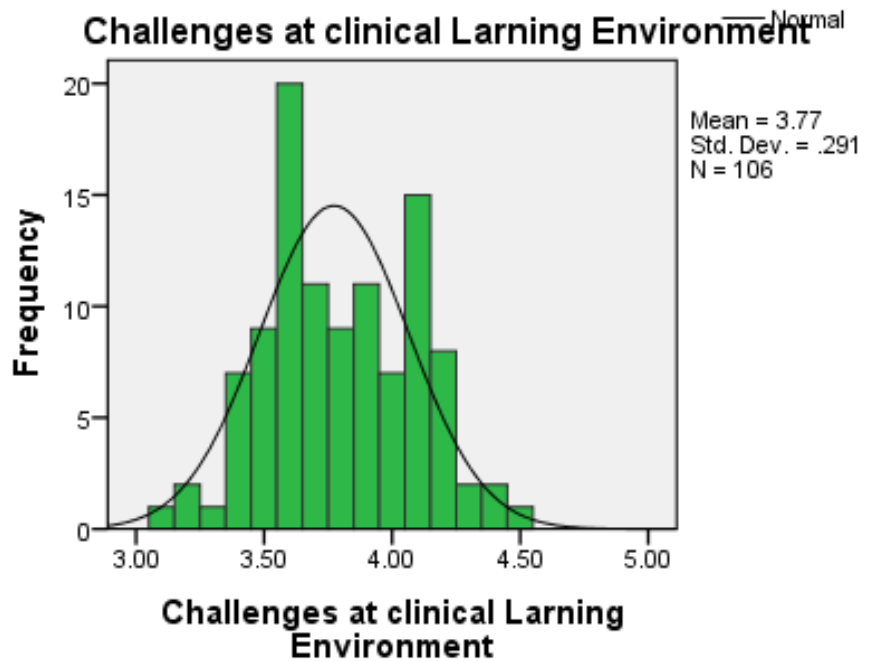

Histogram shows the distribution of the scale Challenges at clinical learning environment.

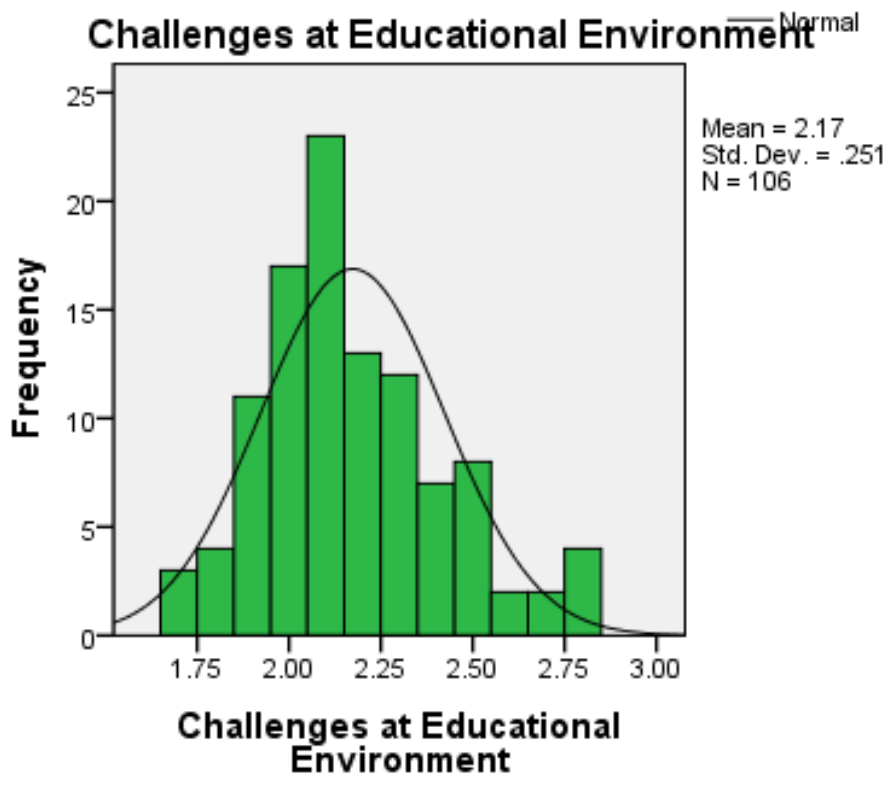

Figure: 2

Histogram shows the distribution of the scale Challenges at educational environment.

\section{Discussion}

Objective in this study was to determine the academic learning and clinical practices challenges in terms of academic and clinical nursing student's points of view. The findings of this study showed that the most important challenges in nursing education was not applying the studies and research done in the clinical practice and this would led to non-evidence based practice. Madarshahian et al. also showed that using evidence based training instead of traditional training would enhance knowledge, skill and high quality caring. As this an important factor in clinical competence, it ought to be included in nursing education (Kenari, 2014).Based on this study, another 
important factor influencing the clinical competence was the educators' role. Cheraghi and Salsali, also reached the same result in their studies (SHARGHI et al., 2015).Baraz et al. propounded presence of interested, and highlyexperienced educators in the University of Medical Sciences as the most important strength of clinical teaching status(SHARGHI et al., 2015) In Masoodi et al.'s study, the educators had referred to lack of a suitable environment, and lack of enough confidence for scientific discussions when necessary, as the two most prominent problems in their work (Masoudi, Afzali, Etemadifar, \& Moghaddasi, 2014) Valizade et al. had also put forward the challenges facing the nursing students throughout their studies such as lack of integration of knowledge and practice, failure to apply the theory (theoretical knowledge) to practice, not using nursing process and scientific principles in clinical environment (Vali Zadeh, Zaman Zadeh, Fathi Azar, \& Safaeian, 2013)Ghodsbin and Shafakhah had also mentioned the students' dissatisfaction with the staff-students rapport and the way of instructing the theoretical and practical courses as two other obstacles in teaching clinical skills. They add that that educators' practical and educational experience, the provision of an environment for students' to experience clinical skills and a sense of responsibility for educators are facilitating factors (Ghodsbin \& Shafakhah, 2014).The represents the clinical educators' key role in teaching, achievement and promotion of nursing students are to the level of clinical competence. Alavi, in his study on educators' roles in clinical education, has mentioned factors such as educators' presence in clinic as a source of reassurance for students, educator as an evaluator, relation establisher, experience provider, motivator, and supervisor, to be very important in learning,. An educator with these features is the effective educator (Alavi \& Abedi, 2016).Michau has also paid attention to the relationship of clinical education and function as an effective factor in creating a theory and practice gap. In his study, he proposed that we should develop a strategy which based on that students could use complementary skills in their internship in order to enhance learning and practical skills (Michau, Roberts, Williams, \& Boyle, 2015).

\section{Conclusion}

This cross-sectional study was done in College of Nursing, Allama Iqbal Medical College of Jinnah Hospital Lahore. So the results may not be generalized. This study evaluated challenges at academic learning and clinical practices among nursing students. The gap between the theory and practice was an important finding. Practicalorientation and traditional view of educators, students and nurses about clinical competency based on practical skills that reduced the need of practice based on knowledge and research. Efforts to reduce the problems between the theory and practice in academic and clinical environment are needed to improve training of student nurses. Also education of professionalism and action based on work environment may be useful.

\section{References}

Al Sebaee, H. A., Aziz, E. M. A., \& Mohamed, N. T. (2017). Relationship between Nursing Students' Clinical Placement Satisfaction, Academic Self-Efficacy and Achievement.

Alavi, M., \& Abedi, H. (2016). Nursing students' experiences and perceptions of effective instructor in clinical education. Iranian journal of medical education, 7(2), 325-334.

Aliakbari, F., Parvin, N., Heidari, M., \& Haghani, F. (2015). Learning theories application in nursing education. Journal of education and health promotion, 4.

Arabshahi, K. S., Haghani, F., Bigdeli, S., Omid, A., \& Adibi, P. (2015). Challenges of the ward round teaching based on the experiences of medical clinical teachers. Journal of research in medical sciences: the official journal of Isfahan University of Medical Sciences, 20(3), 273.

Bandura, A., \& Walters, R. H. (1977). Social learning theory (Vol. 1): Prentice-hall Englewood Cliffs, NJ.

Baraz, S., Memarian, R., \& Vanaki, Z. (2015). Learning challenges of nursing students in clinical environments: A qualitative study in Iran. Journal of education and health promotion, 4.

Bawadi, H., Norrie, P., \& Debbie, M. D. Student Nurses' Perceptions of a Good Mentor: A Questionnaire Survey of Student Nurses in the UK, USA and Jordan.

Bisholt, B., Ohlsson, U., Engström, A. K., Johansson, A. S., \& Gustafsson, M. (2014). Nursing students' assessment of the learning environment in different clinical settings. Nurse education in practice, 14(3), 304-310.

Cheraghi, M. A., Salsali, M., \& Safari, M. (2010). Ambiguity in knowledge transfer: the role of theory-practice gap. Iranian journal of nursing and midwifery research, 15(4), 155.

Dafogianni, C., Alikari, V., Galanis, P., Gerali, M., \& Margari, N. (2015). Nursing Students' Views on their Clinical Placement in Pediatric Hospitals of Athens, Greece. International Journal of Caring Sciences, 8(3), 673.

Fairbrother, M., Nicole, M., Blackford, J., Nagarajan, S. V., \& McAllister, L. (2016). A New Model of Clinical Education to Increase Student Placement Availability: The Capacity Development Facilitator Model. AsiaPacific Journal of Cooperative Education, 17(1), 45-59.

Ghodsbin, F., \& Shafakhah, M. (2014). Facilitating and preventing factors in learning clinical skills from the viewpoints of the third year students of Fatemeh school of nursing and midwifery. Iranian journal of medical education, 7(2), 343-352.

Grimm, K. L. (2017). The Relationship Between Pre-Licensure Employment and Student Nurse Self-Efficacy. 
Walden University.

Hagos, F., Alemseged, F., Balcha, F., Berhe, S., \& Aregay, A. (2014). Application of nursing process and its affecting factors among nurses working in mekelle zone hospitals, Northern Ethiopia. Nursing research and practice, 2014.

Harinie, L. T., Sudiro, A., Rahayu, M., \& Fatchan, A. (2017). Study of the Bandura's Social Cognitive Learning Theory for the Entrepreneurship Learning Process. Social Sciences, 6(1), 1.

Hussein, R., Everett, B., Ramjan, L. M., Hu, W., \& Salamonson, Y. (2017). New graduate nurses' experiences in a clinical specialty: a follow up study of newcomer perceptions of transitional support. BMC nursing, 16(1), 42.

Ismail, L. M.-N., Aboushady, R. M.-N., \& Eswi, A. (2015). Clinical instructor's behavior: Nursing student's perception toward effective clinical instructor's characteristics. Journal of Nursing Education and Practice, 6(2), 96.

Jackson, B. A. (2015). Nursing Students' and Novice Clinical Instructors' Experiences With Clinical Instruction and Assessment. Walden University.

Jamshidi, N., Molazem, Z., Sharif, F., Torabizadeh, C., \& Najafi Kalyani, M. (2016). The challenges of nursing students in the clinical learning environment: a qualitative study. The Scientific World Journal, 2016.

Kenari, M. A. (2014). Effect of evidence-based method clinical education on patients care quality and their satisfaction. Advances in Applied Sociology, 4(02), 59.

Khalil, A., Majeed, M. A. I., Bio, A. W., \& Gilani, S. A. (2017). ASSESSMENT OF NURSING STUDENT PERCEPTION TOWARDS, NURSING PROFESSION IN SIR GANGA RAM HOSPITAL AND ITTEFAQ HOSPITAL TRUST LAHORE, PAKISTAN.

Koy, V. (2015). Perceptions of nursing students on effective clinical preceptors in Phnom Penh National Hospitals, Cambodia. International Journal of Research in Medical Sciences, 3(7), 1605.

Liu, Y., \& Aungsuroch, Y. (2018). Current Literature Review of Registered Nurses' Competency in the Global Community. Journal of Nursing Scholarship.

Masoudi, R., Afzali, S. M., Etemadifar, S., \& Moghaddasi, J. (2014). Investigating the degree of self-efficacy perception and role performance of nursery and midwifery college instructors in practical education. Journal of Shahrekord Uuniversity of Medical Sciences, 10.

Michau, R., Roberts, S., Williams, B., \& Boyle, M. (2015). An investigation of theory-practice gap in undergraduate paramedic education. BMC Medical Education, 9(1), 23.

Papathanasiou, I. V., Tsaras, K., \& Sarafis, P. (2014). Views and perceptions of nursing students on their clinical learning environment: Teaching and learning. Nurse Education Today, 34(1), 57-60.

Rafiee, G., Moattari, M., Nikbakht, A. N., Kojuri, J., \& Mousavinasab, M. (2014). Problems and challenges of nursing students' clinical evaluation: A qualitative study. Iranian journal of nursing and midwifery research, $19(1), 41$.

Shahzadi, C., Kousar, R., Hussain, M., Waqas, A., Gilani, S. A., \& Safdar, M. (2017). The Assessment of Gap between Theory and Training Classes in Nursing Education System: A Case of University of Lahore, Pakistan.

SHARGHI, N. R., ALAMI, A., KHOSRAVAN, S., MANSOORIAN, M. R., \& EKRAMI, A. (2015). Academic training and clinical placement problems to achieve nursing competency. Journal of advances in medical education \& professionalism, 3(1), 15.

Vali Zadeh, L., Zaman Zadeh, V., Fathi Azar, A., \& Safaeian, A. (2013). Barriers and facilitators of research utilization among nurses working in teaching hospitals in Tabriz. Journal of hayat, 8(2), 32-42.

Zhou, F., Maier, M., Hao, Y., Tang, L., Guo, H., Liu, H., \& Liu, Y. (2015). Barriers to research utilization among registered nurses in traditional Chinese medicine hospitals: a cross-sectional survey in China. Evidence-Based Complementary and Alternative Medicine, 2015. 